\title{
Ways of forming legal consciousness in people with hearing impairment
}

\author{
Elena Koltunova ${ }^{1, *}$ and Galina Vlasova $^{2}$ \\ ${ }^{1}$ State public educational establishment of Rostov region Rostov regional center of education of the \\ deaf students (RRCEDS), Rostov-on-Don, 344022, Russia \\ ${ }^{2}$ Rostov branch of the Russian State University of Justice, Rostov-on-Don, 344038, Russia
}

\begin{abstract}
The article presents an analysis of the results of a study aimed at studying the formation of legal awareness in students with hearing defects. Features of the legal consciousness of this contingent have become an independent subject of psychological analysis. Legal awareness as a form of social consciousness is considered as a legal mediation and awareness of social phenomena. In accordance with the way legal phenomena are reflected in the legal consciousness, legal ideology and legal psychology are distinguished. The latter is directly dependent on the level of development of legal science. This means that legal awareness is a product of public consciousness and the result of individual, personal understanding. At the same time, it is legal psychology that determines the degree of effectiveness of legal ideology. If legal ideology is a certain system of views, theories and concepts that express the understanding of law in society, then legal psychology is feelings, moods, certain behavioral attitudes and orientations associated with the legal phenomena that are observed in this state and society. Attention should be paid to the characteristics of legal awareness as a general psychological category. This article analyzes the formation of legal awareness in hearing-impaired children, based on the experience of sign language teachers of the Rostov-on-don state educational institution.
\end{abstract}

\section{Introduction}

Legal consciousness is one of the fundamental factors of the integrity and security of society. The problem of legal consciousness has long been the object of research of Russian scientists. In the "Golden age" of Russian jurisprudence, issues of legal consciousness were tackled by I. A. Ilyin, B. A. Kistyakovsky, P. I. Novgorodtsev, L. I. Petrazhitsky, and B. N. Chicherin. Since the second half of the twentieth century, it has been intensively studied by Soviet scientists. the works of V. A. Syrtseva, I. E. Farber, E. A. Lukasheva, V. A. Segarcea, V. I. Malakhova, Y. K. Pogrebnoy were indicative in this respect. In her monograph Yu. K. pogrebnaya noted that "legal consciousness should be defined as a set of meanings and content born when the nature and essence of law, the legal level of relations between people is being realized" (Pogrebnaya, 2013, P. 18).

Today in Russian legal science, legal consciousness as a form of social consciousness is considered to be a legal mediation and consciousness of social phenomena, "it is a form of

\footnotetext{
*Corresponding author: 4015821@gmail.com
} 
consciousness of law as a specific phenomenon of social reality" (Nersesyants, 2004, P. 267). However, legal consciousness cannot be considered in any one coordinate system. It is necessary to keep in mind the specifics of the interpretation of legal consciousness in the context of various humanities. First of all, it should be noted that if we proceed from the depth legal phenomena reflection, we can distinguish the ordinary and theoretical levels of legal consciousness. And in accordance with the way legal phenomena are reflected in the legal consciousness, legal ideology and legal psychology are distinguished. Moreover, at the beginning of the twentieth century, it was emphasized that "people's legal consciousness can stand at a height only where legal science stands at a height" (Nersesyants, 2004, P. 160), which is the main content of legal ideology.

On the one hand, legal consciousness is a product of public consciousness, and on the other - the result of individual, personal comprehension. It should be understood that there is a close relationship between the level of development of legal consciousness and the level of conception formation of an individual. First of all, the mass consciousness reflects in the ideas, beliefs, ideals, attitudes and habits. It should be emphasized that it is legal psychology that determines the degree of effectiveness of legal ideology. After all, if legal ideology is a certain system of views, theories and concepts in the field of law that expresses the understanding of law in society, then legal psychology is feelings, moods, certain behavioral attitudes and orientations associated with those legal phenomena that take place in a given state and society. Therefore, it is necessary to pay attention to the characteristics of legal consciousness as a general psychological category (Leontiev, 2014).

\section{Materials and methods}

The following methods and techniques were used to solve the tasks set in the article:

1. Analytical-synthetic polysensory concentric method using an abbreviated system of phonemes. (Rau, Slezina, 1981).

2. Method of developing auditory perception, according to which persons with hearing impairments are trained to distinguish speech on an auditory basis (by reading from the lips) and by hearing (behind the screen) (Kuzmicheva, Yakhnina, 2011; Kuzmicheva, 1999; Nazarova, 2001).

3. E. I. Leonhard's Pure oral method, which includes 4 vectors: - early diagnosis; - early hearing prosthetics; - early learning; - interaction with the family (parents) and their maximum assistance in training and rehabilitation. (Zykov, 1977).

4. Didactic method of meaning formation and development of life-meaning strategies.

5. Support in the work on the sign-symbolic system).

6. Reliance on the questionnaire of O. V. Protasova "Jurisprudence".

7. Project Method (project activity).

\section{Discussion}

Features of legal consciousness in individuals depend on the meaning of life orientations, value regulators of behavioral activity, strategies for self-realization and self-management. The development of individual legal consciousness is directly related to legal education, which is an integral element of the ideological function of any state. It is a "purposeful systematic activity of the state, its bodies and their employees, public associations and work community to form and improve the legal consciousness and legal culture" (Vlasov, Vlasova, Denisenko, 2017, P. 338).

Every Russian citizen with an active civil position seeks to direct their efforts and will to improve life indicators, to change outdated stereotypes and models in various spheres of 
public activity, to establish and develop better and stronger relationships between people, to master innovative computer developments, to obtain information technologies. Living and developing in a state governed by the rule of law, people learn the rules and culture of behavior, normative documents, legal bases and norms, and legislative acts from childhood. Family, educational environment, work, social circle and range of communication, level of self-consciousness, understanding of one's goal and place in life contribute to the formation of legal competencies. Under the influence of these factors, modern youth acquire knowledge and experience that are basic and serve as a support for them in life, help them navigate the world, implement their plans, reach heights, create and build.

The constantly changing paradigm of education, clarifications and additions in legal documents affect the development of a clear civil position and priorities of each individual, their views, determine their aspirations and social status, aim at spiritual growth, study the history of their country and other States, introduce them to centuries-old cultural values, help expand their legal field and level of legal consciousness. I. A. Ilyin describes legal consciousness as "the body without which it is impossible to live by law, enter into legal relations with other people, maintain law and order" (Ilyin, 1997, P. 112). Thus if children with normal development absorb incoming information from the surrounding world through all available analyzers, then in children with hearing impairment, the auditory analyzer may simply fall out, malfunction, or function insufficiently. In connection with different nature of hearing loss in children the classification is as follows:

- hard-of-hearing babies - babies with minor hearing impairments;

- deaf-children who have almost no hearing (high rates of decline);

- deaf children with a complex structure of the defect - cerebral palsy (cerebral palsy), visual impairment up to blindness, severe disorders of cognitive activity, autism spectrum disorders (ASD)

- children with cochlear implants (CI) - children after surgery "to implant electrode systems in the inner ear in order to restore auditory sensation by direct electrical stimulation of the afferent fibers of the auditory nerve" (Algman, 2003, P. 93). This method allows children with CI to master the communicative function of speech and communicate on a new sensory basis;

- late deafness-a contingent who lost their hearing in an accident, as a result of illness, after taking antibiotics, during a period when the main speech functions or speech were already formed.

Children with hearing impairments are disabled children, whose success is constantly monitored by our state. Federal law No. 273-FZ of December 29, 2012 "On education in the Russian Federation " clearly defines priority tasks in education and establishes the right for persons with disabilities to receive a full-fledged quality education without discrimination on an equal basis with children who do not have health disabilities (Kauffman \& Badar, 2014).

The articles of the law "On education in the Russian Federation" devoted to inclusive education contain a mechanism for ensuring full access to the necessary knowledge for this category of students. As a result, individuals with hearing impairment cannot be diminished in any way. They are equal citizens of the Russian state.

According to the outstanding psychologist L. S. Vygotsky, the task of educating a child with a developmental disorder is a social, not biological, task, in which the teacher is faced with the social consequences of a physical defect, and not with biological factors. In practice, workarounds are used to compensate for the defect and integrate the child with hearing impairments in the socialization process (Vygotsky, 1995). Children with hearing loss experience difficulties. They always wear individual hearing aids. Children either do not hear the speech that sounds, or perceive it with distortions: inaccuracies in words, sounds, construction of phrases, and the semantic component of sentences. They try to perceive the contours of words, individual vowel sounds, try to catch well - known worked-out words. 
Since the process of speech development in deaf children does not occur independently, children are taught to master speech.

Children with hearing disabilities, according to the specifics of their defect, are trained in specialized kindergartens, in educational institutions of types I and II: schools, boarding schools, centers where, along with evoking, setting, automating of sounds, forming pronunciation, intensive work is carried out to develop the speech (residual) hearing of non - hearing schoolchildren, relying on compensatory analyzers when using sound-amplifying equipment for collective use or an induction loop in group classes. "In an adult, a violation of the activity of the auditory analyzer leads to problems of oral communication. Hearing impairment at an early age affects the course of a child's mental development, resulting in a number of secondary developmental abnormalities, primarily in the formation of speech" (Zykov, 1977, P. 125).

To date, a great experience has been accumulated in Russian sign language teaching, correctional psychology, developmental and educational psychology, and an integral system of formation of oral speech as one of the factors of comprehensive development of a deaf student, contributing to the most complete social adaptation has been built (K. A. Volkova, S. A. Zykova, T. S. Zykova, E. p. Kuzmicheva, L. p. Noskova, F. F. Rau, N. F. Slezina, N. D. Shmatko, N. D. Yyakhnina).

While the sight is preserved, a visual analyzer and tactile - vibration are regarded highly significant, with them you can successfully establish speech kinesthesia based on reserve hearing in a deaf student: repeat and fix articulation patterns by imitation, develop a speech apparatus where the compensatory function of the visual analyzer helps to form and master the skills of reading from the lips. The tactile-vibration analyzer registers the effect of tactile impulses on the skin: pressure, vibration, touch, and breath. And in the direction of the air stream and vibration, the sounds of speech and its tempo are set, breathing, voice strength, dance elements are worked out, and impulses are received through the induction loop during dancing.

As part of the modernization of education and successful learning of pupils with hearing impairments knowledge and skills are introduced in the learning process beyond the basic educational program and adapted programs, individual learning routes (maps), approved and introduced standards for primary basic education GES LHA, completion and the imminent introduction of Federal state educational disabilities for the rest of the trainees is scheduled. Since hearing-impaired students spend most of their time in boarding schools and are limited in communication, the responsibility assigned to educators and teachers is enormous (Akamed, Kian, Yildirim, 2017). After all, competence of a teacher depends on the overall level of development of the children they train, on how firmly the concepts of morality, order, training, responsibility, legality, education, culture of behavior, duty, historical heritage, law will enter their lives. All those necessary aspects, without which it is impossible to exist in a team, in a family, in a city, in a state, without which it is impossible to form a legal consciousness (Howe \& Miramontes, 2015). Together with parents and teachers of clubs and sections, children should be systematically trained to live in accordance with the norms and requirements of morality, in compliance with the laws of the society to which they belong.

People with hearing loss are representatives of a special group, a special society that has its own historical roots (history), cultural heritage, and bilingualism.

1. Dactyl speech - a set of signs, each corresponding to a certain letter, a letter in the air, according To L. S. Vygotsky.

2. Sign language, accompanied with very expressive emotional facial expressions, and, if possible, an oral form of speech. Sign language has two types: formative and colloquial, as well as its own specifics: 1 . a single gesture can be used for several words or concepts; 2 . different parts of speech (noun, verb) can be indicated by a single gesture; 
3. A sentence composed in sign language does not preserve the sequence of its verbal expression: the absence of prepositions, prefixes, inflections, the use of negatives after verbs; 4. inclusion of dactylic elements in sign language, as a result of which prepositions and endings are dactylated in words (Bogdanova, 2002).

L.Vygodsky paid attention and characterized simultaneous possession of several kinds of polyglossia that serves the basis of the oral speech formation (Vygodsky, 1995).

Modernization of the modern education system is aimed not only to enrich students with knowledge, teach them to use it, but also to give a new life to this knowledge, skills and abilities and bring them to the value-semantic level. The concepts that appear in the learning process: meaning, content, sign, symbol make us transform techniques, rethink and deepen technologies in teaching deaf and hard-of-hearing students. It should be understood that the meaning is a kind of shell of the word (indicator), which contains the meaning that makes up the content of the word. Signs, like meaning, perform only a service function and indicate objects. Concepts, meaning, and symbols are the next level of knowledge. This is especially true for a symbol that is incredibly original, self-sufficient, rich, multi-faceted, bright and extremely attractive. "A symbol is a vector-directed bundle of meanings" (Fomenko, Abakumova, 2010, P. 91).

$\mathrm{He}$ is assigned the mission of broadcasting them. Symbols incorporate the spiritual component of ancient civilizations, their historically developed culture. In turn, culture can be understood "as semantic interpersonal communication and considered in its textual state, where the meanings encoded in it cannot be underestimated" (Fomenko, Abakumova, 2010, P. 62).

The introduction of the sign - symbolic system into the educational process did not only diversify approaches to presenting the material, but also facilitated the task of comprehension, enriched the vocabulary, expanded the range of ideas and concepts, helped to strengthen spirituality and morality, assimilation of rules of behavior and moral norms, and increased motivation to teach students with hearing analyzer pathology. And, relying on this system in the legal context, it contributed to the assimilation of knowledge in the field of legal consciousness. State educational institution of Rostov region Rostov regional center of education of deaf students (RRCEDS) to the process of evolution of consciousness has a complex approach.

In addition to the program of General education subjects "social Studies"," fundamentals of state and law", the course of individual lessons on" formation of the pronunciation side of speech and development of speech hearing "includes some topics that cover legal aspects: individual chapters of the country's basic law-the Constitution;" Know and respect the law," "Rights and obligations of students of RRCEDS" and other topics. An in-depth knowledge of legal provisions allows children with hearing impairment to improve their level of legal literacy. The classes use a variety of techniques. They include familiarization with a set of legal norms and requirements, the accumulation of legal vocabulary, working with computer technologies, and the use of interactive forms of training. In addition, students of the center are regularly informed about the directives of the Ministry of education that directly effects the students of the Center, as well as about orders and regulations for the educational institution.

During the educational process, optional classes on legal culture are held, where students get acquainted with the cultural and legal heritage of various peoples of the world. Extracurricular activities are organized to consolidate important legal concepts. We are talking about quizzes, games, leisure evenings, Amateur performances, festive matinees. The center organizes excursions to places of military glory. You can visit museums not only in Rostov-on-don and the cities of the Rostov region, but also in other regions of Russia. In addition, thanks to sponsorship, students of the Center were able to visit such countries as Austria, Great Britain, Germany, Greece, Poland, France and Turkey. They got acquainted 
with the law and order in these countries of the past and present. Much attention is paid to the legal culture. In particular, students got acquainted in detail with the statue of the goddess of justice (in Greek mythology - Themis, in Roman-Justice) (Dixon, 2014).

They were told that every detail in the statue of Themis (or justice) is symbolic and has meaning. The blindfold of Themis is a symbol of impartiality. Libra is a measure of good and evil, as well as justice itself. In Roman tradition, a sword was added to the attributes of the goddess - a symbol of bringing to justice for violating the law.

Thus, deaf and hard-of-hearing children develop their legal culture and, consequently, their legal consciousness both during school and after school hours. As part of their project activities, they collect and process a large amount of material, take a lot of photos, make presentations and have reports.

In their messages, students of the Center compare the law and order that took place in the past with those that are observed today. They pay great attention to legal symbols. In particular, they found out that the judicial mantle is a symbol of state power, its black color means authoritarianism and impartiality. The judge's hammer is a symbol of the indisputability of the verdict or decision of the judge, and the square, academic headdress is a symbol of the solemnity of the trial. From all the above, it follows that achieving the goals of legal education - mastering legal knowledge, forming high legal culture and developing legal consciousness in children with hearing analyzer disorders is quite possible, thanks to the multifaceted work of teachers to bring the Arsenal of acquired knowledge to a new valuesemantic level, despite the difficulties of the cognitive, emotional and personal plan of students.

\section{Conclusion}

Legal upbringing is closely connected with legal education. This is a single purposeful process of forming the consciousness of a law-abiding person (Fox, 2020).

At the same time, representatives of different age groups have certain features of legal consciousness that have meaningful (personal-evaluative understanding of legal norms) and dynamic (readiness to act in accordance with legal norms) differences depending on age and gender.

During the laying of the foundations of justice a child must understand that the sense of justice is not a simple acquaintance with the law, its principles and requirements coloured with a certain evaluative attitude (the principle of "good - bad"), but should reflect the level of personal partiality to the legal regulation of his own life, reflecting the saturation level of the personal meaning of those aspects of behavior which are governed by existing legal norms.

All of the above allows to conclude that due to a certain set of psychological and pedagogical methods, the process of forming legal consciousness in children with a defect in the auditory analyzer can achieve significant results (Prokofieva, 2013).

\section{References}

1. I.V. Abakumova, I.A. Belokon, D.V. Melnichenko, Psychological and didactic features of the formation of value-semantic attitudes in the educational process: guidelines (CREDO, Moscow, 2011)

2. I.V. Abakumova, E.A. Koltunova, Psychological features of symbolization in nonhearing people in the period of youth (CREDO, Moscow, 2013)

3. J. Akamed, N. Kian, A. Yildirim, Cyprus journal of educational Sciences 12(4), 202217 (2017) doi: https://10.18844/cjes-да.v12i4.2902 
4. A.Ya. Algman, G.A. Tavartkiladze, Guide to audiology (DMK-Press, Moscow, 2003)

5. T.G. Bogdanova, Surdopsychologiya (Akademiya, 2002)

6. L.J. Chua, D.M. Engel, Annual Review of Law and Social Science 1(15), 335-353 (2019)

7. F.A. Dixon, N. Yssel, J.M. McConnell, T. Hardin, Journal for the Education of the Gifted 37(2), 111-127 (2014) doi: 10.1177/0162353214529042

8. V.T. Fomenko, I.V. Abakumova, News of the Chechen state pedagogical Institute 1(5), 56-65 (2010)

9. M.P. Fox, Qualitative sociology 43, 111-142 (2020)

10. V. Frankl, Man in search of meaning (Big Press, Moscow, 2012

11. K.R. Howe, O. Miramontes, Ethics of special education (Teachers College press, New York, 2015) https://www.worldcat.org/title/ethics-of-specialeducation/oclc/1022977104

12. J.M. Kauffman, J. Badar, Journal of International Special Needs Education 17(1), 1320 (2014) https://eric-ga.ed.gov/?id=EJ1090816

13. E.A. Koltunova, Features of diagnostics of symbolization in non-hearing high school students (CREDO, Moscow, 2013)

14. E.A. Koltunova, Symbol and symbolization: similarity and differences of interpretations in the context of various psychological approaches (CREDO, Moscow, 2012)

15. E.P. Kuzmicheva, E.Z. Yakhnina, Teaching deaf children to perceive and reproduce oral speech (Akademiya, Moscow, 2011)

16. E.P. Kuzmicheva, Method of development of auditory perception of deaf students: manual for teachers (Education, Moscow, 1999)

17. D.A. Leontiev, General theory of meaning, psychological concepts of meaning formation, meaning didactics (CREDO, Moscow, 2014)

18. L.P. Nazarova, Methods of development of auditory perception in deaf children with hearing disorders (Vlados publishing house, Moscow, 2001)

19. V.S. Nersesyants, Problems of the General Theory of Law and State: Textbook (InfraM, Moscow, 2014)

20. Yu.K. Pogrebnaya, Crisis of modern Russian legal consciousness (Infra-M, Moscow, 2016)

21. N.V. Prokofieva, Moral reflection as a factor of harmonic development of the individual (CREDO, Moscow, 2013)

22. F.F. Rau, N.F. Slezina, Methods of teaching pronunciation in the school of the deaf: A Guide for teachers (Prosveshchenie, Moscow, 1981)

23. V.I. Vlasov, G.B. Vlasova, S.V. Denisenko, Theory of state and law (Phoenix, Rostovon-Don, 2017)

24. L.S. Vygotsky, Principles of social education of deaf and dumb children (Prosveshchenie, Moscow, 1995)

25. L.S. Vygotsky, Thinking and speech (Labyrinth, Moscow, 1999)

26. S.A. Zykov, Methods of teaching deaf children the language (Prosveshchenie, Moscow, 1977) 